\title{
Estudio de niveles de Immunoglobulina A secretora en secreción salival de niños sanos
}

\author{
*Dr. Edyardo Tomasello H., **Q.F. Luz Arévalo F., "**María E. Fuenzalida C., ****Emilio Torres Kameid.
}

\section{ABSTRACT}

\begin{abstract}
The leveis of secretory Ig A in our country have not been determined, there are only figures for under seven years old, which have been reported by the Immunology Department of the Chilean Public Health Institute.

The concentration of secretory Ig A were measured in 233 samples of saliva obtained from healthy children from the Consultorio Hospital de Niños and the Nursery of Matemity Hospital Enrique Deformes whose ages were between one day and seven years.

The measures were made by Radial Immunodifusion using antiserum anti IgAS and lgAS standard of the Department of Immunalogy of the Chilean Public Health Institute. The mean concentration was established for each group. The wide dispersion of values prevented us from obtaining normal values.

No definite correlations were observed between time of abstinence and the level of secretory Ig A; and between this level and natural feeding.
\end{abstract}

La determinación de distintos parámetros normales de inmunología del adulto está estudiada, no así en la infancia, donde las cifras consideradas como normales sufren gran variación.

Siguiendo una línea de investigación nos propusimos determinar las cifras de Inmunoglobulina A secretora (Igas), en nin̄os aparentemente normales y sanos de nuestra población infantil, desde el recién nacido hasta los 7 años.

La Igas ha sido menos estudiada que la sanguínea. Se sabe que es semejante en todo el sistema secretor extemo y que cumple un importante rol protector contra virus y bacterias; otra función parece ser la prevención de enfermedades alérgicas al unirse con los antígenos que normalmente se ingieren en los alimentos o que entran por via aérea.

La producción de esta Igas está favorecida por infecciones naturales e inmunizaciones.

La relación entre Igas e Iga sanguínea suele ser variable; asi en caso de deficiencia selectiva de Iga, que es la inmunodeficiencia primaria más frecuente en el hombre $(0,14-0,2 \%$ de la población), la lgas habitualmente está en valores bajos o nulos, descubriéndose un componente secretor libre. Muchos individuos con esta deficiencia son asintomáticos, pero un número no despreciable de ellos padece problemas clínicos como: infec-

\footnotetext{
- Depto. Pediatria, Universidad de Chile, Valparaiso.

** Laboratorio Inmunologia, Hospital Ven Buren.

-** Interna Quimica y Fammacia, Unjverstdad de Chile, Valparaisso.

**** Inteino Quimica y Farmacia, Universidad de Chile, Valparalso.
}

ciones crónicas, recurrentes de vías respiratorias altas y bajas, rinitis alérgica, asma rebelde, hemosiderosis pulmonar, enfermedad celíaca, cáncer y enfermedades autoinmunes, particularmente lupus eritematoso diseminado $y$ artritis reumatoidea.

Nos propusimos además estudiar la relación de Igas en los niños alimentados con leche matema, por sus conocidas propiedades de aporte de esta inmunoglobulina, y la relación con el tiempo de ayuno, en el momento de obtención de la muestra, en busca de posibles variaciones.

\section{MATERLALES Y METODO}

A 233 niños sanos, provenientes del consultorio Hospital de Niños de Valparaiso y recién nacidos de la maternidad del Hospital Enrique Deformes, se les determinó el nivel salival de Igas.

Se escogieron niños clínicamente sanos, sin antecedentes de patologías en los últimos 15 días y sin carencias nutricionales.

Para lograr los objetivos del trabajo fue necesario separar el total de niños estudiados, en diferentes grupos etarios, lo que se realizó de la siguiente manera:

$\begin{array}{llllr}0 & - & 15 \text { días } & = & 15 \\ 15 \text { días } & - & 1 \text { mes } & = & 7 \\ 1 \text { mes }- & 6 \text { meses } & = & 44 \\ 6 \text { meses }- & 1 \text { año } & = & 33 \\ 1 \text { año }-2 \text { años } & = & 45 \\ 2 \text { años }-\quad 4 \text { años } & = & 56 \\ 4 \text { años - } 7 \text { años } & = & 33\end{array}$


La secreción salival se obtuvo directamente mediante un gotario y se recogió en frasco estéril, refrigerándose inmediatamente.

Para la cuantificación de la muestra se utilizó el método de inmunodifusión radial, que consiste fundamentalmente en sembrar la muestra, junto a patrones de Igas pura, de concentraciones conocidas, sobre un gel de agar mezclado con suero mono-específico anti Igas. Se deja la placa en refrigeración en cámara húrneda, durante 72 horas, al cabo de las cuales se observa un halo de precipitación alrededor de los patrones y muestras sembradas. Dichos halos se miden y se procede a construir la curva patrón (diámetro del halo versus concentración de Igas pura) para determinar las concentraciones de cada muestra por interpolación.

Es importante destacar que en algunos casos fue necesario sembrar más de una vez la misma muestra, para así conseguir un halo de precipitación cuantificable; debiendo, en estos casos, considerar el número de siembras al calcular la concentración de Igas en la muestra.

La Igas pura usada en la experiencia fue donada por el Departamento de Inmunología del Instituto de Salud Pública de Chile, en donde se obtuvo a partir del calostro, el cual se centrifuga, se desengrasa con silica gel al $1 \%$ enseguida se diaJiza con buffer fosfato de $\mathrm{pH} 7 \mathrm{y}$ se filtra por el gel G 200 para luego cuantificarla con suero anti Igas standard mediante inmunodifusión radial.

El suero mono-especifico anti Igas también fue donado por dicho Instituto $y$ se consigue por inmumización con animales de experimentación, purificándose luego mediante columnas de afinidad las veces que sea necesario, hasta obtener el suero anti Igas puro.

Estos reactivos: Igas puro (Dip 2) y suero anti Igas (serie N. ${ }^{\circ}$ ) se almacenan en refrigeración a una temperatura adecuada para mantener su estabilidad (aproximadamente $-20^{\circ} \mathrm{C}$ ).

El método elegido para la cuantificación de Igas fue inmunodifusión radial, por ser éste el usado en clínica.

\section{RESULTADOS}

Los resultados de la deterninación de Igas salival se muestran en los siguientes gráficos:

\section{Gráfico N. ${ }^{\circ}$ :}

En este gráfico aparecen las concentraciones promedio de Igas salival en los diferentes grupos etarios, destacándose la escasa cantidad de Igas

Gráfico 1

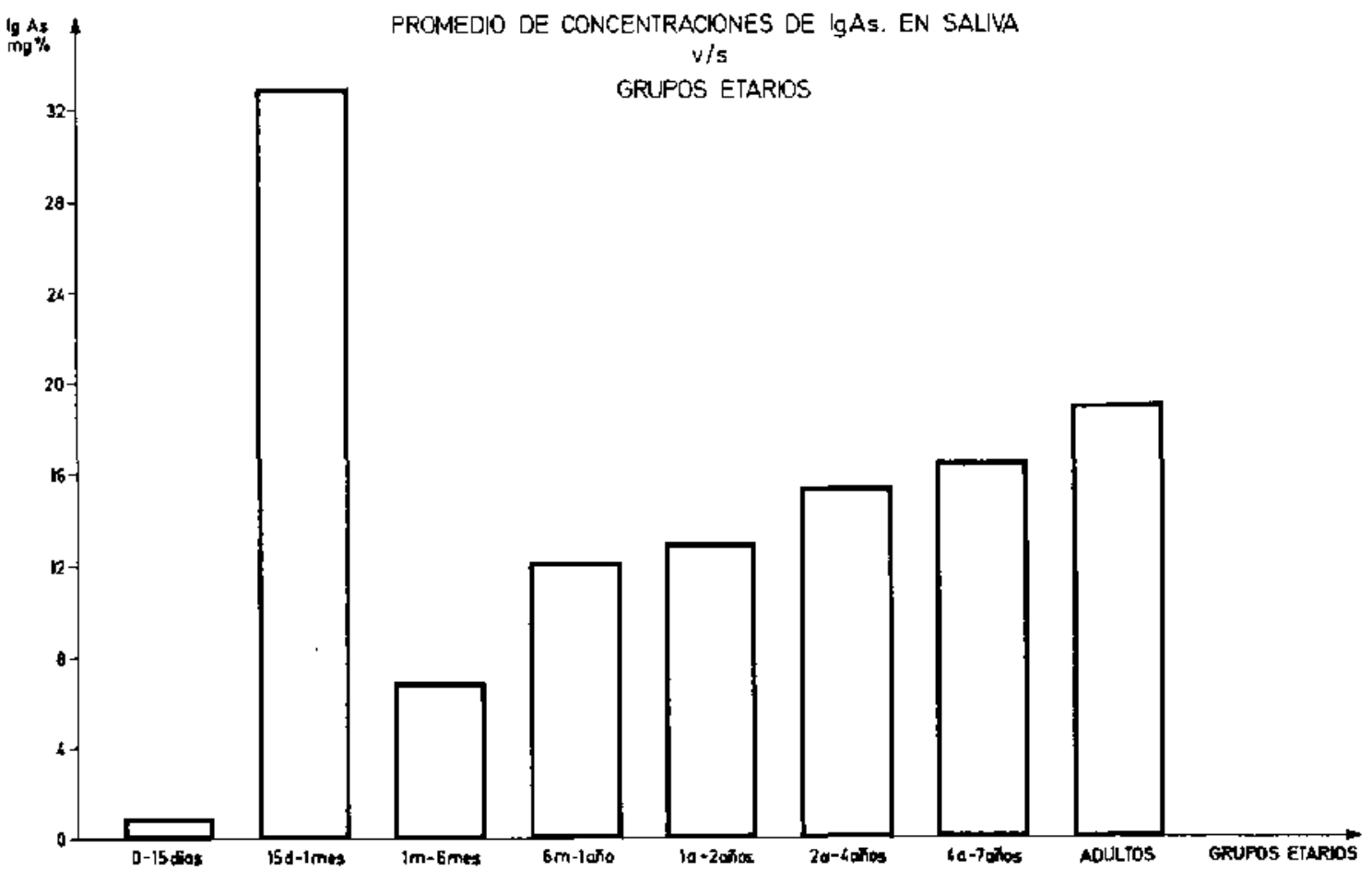


(0,97 mg\%) en el grupo de 0-15 días; posteriormente se observa un aumento notorio $(32,89 \mathrm{mg} \%$ entre 15 y 30 dias), para luego disminuir bruscamente (6,89 mg \% entre 1 y 6 meses) y en seguida aumentar paulatinamente hasta alcanzar los valores del adulto (19 mg \%), estandarizado por el Departamento de Inmunología del Instituto de Salud Pública de Chile. Los valores promedios encontrados para los diferentes gnupos etarios son:

\begin{tabular}{|c|c|c|c|}
\hline 0 & - & 15 días & $0,97 \mathrm{mg} \%$ \\
\hline 15 días & - & 1 mes & $32,89 \mathrm{mg} \%$ \\
\hline 1 mes & - & 6 meses & $6,89 \mathrm{mg} \%$ \\
\hline 6 meses & - & 1 año & $12,13 \mathrm{mg} \%$ \\
\hline 1 & - & 2 años & $12,95 \mathrm{mg} \%$ \\
\hline
\end{tabular}

$$
\begin{array}{llll}
2 & - & 4 \text { años } & 15,40 \mathrm{mg} \% \\
4-7 \text { años } & 16,44 \mathrm{mg} \%
\end{array}
$$

\section{Gráfico $N^{0} 2$}

Aquí se observa la evolución de los niveles de Igas salival a través del tiempo desde el recién nacido hasta los 7 años inclusive.

\section{Gráfico N. 3}

En este grafico se observa la amplia dispersión de las concentraciones de Igas obtenidas, motivo por el cual no se logró obtener un rango de valores normales para cada grupo etario, pudiendo sólo detemminarse los valores promedios para cada uno de ellos.

Gráfico 2

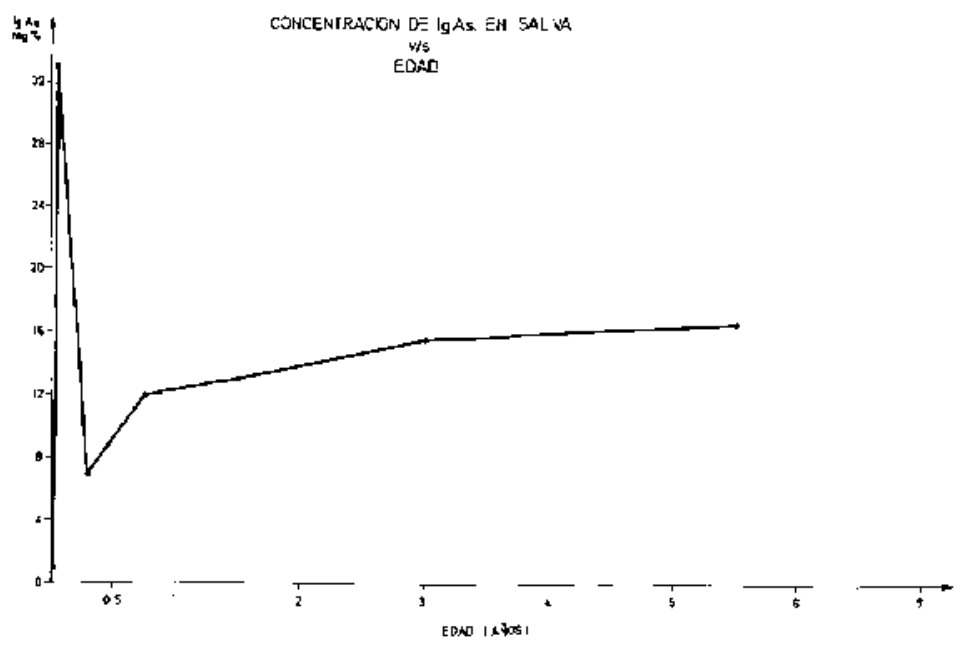

Gráfico 3

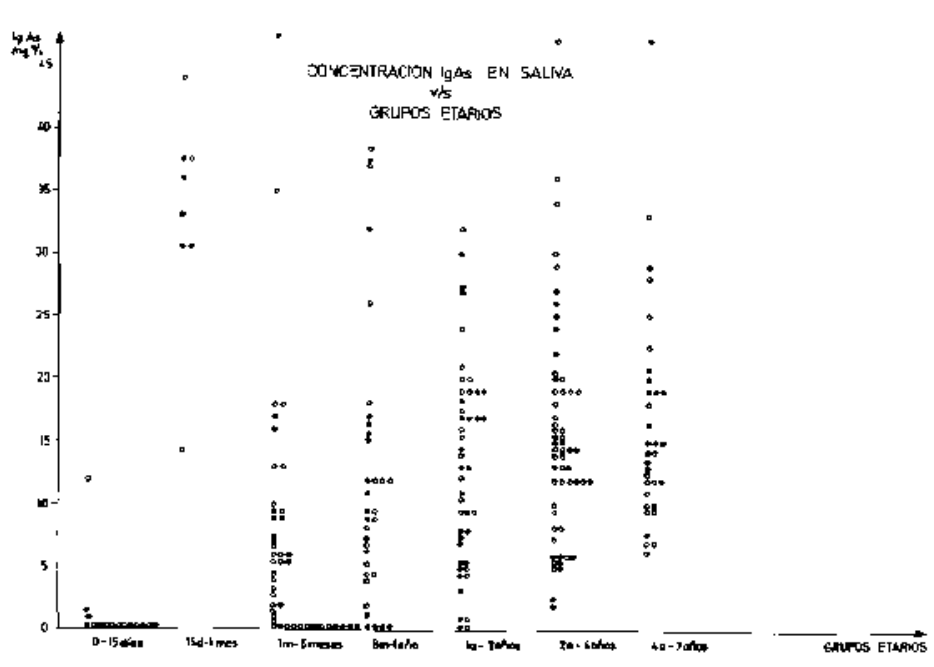




\section{Gräficos N. ${ }^{\circ} 5$ y 5}

En vista de la gran dispersión observada en los resultados del gráfico anterior, se analizaron dos grupos etarios, por separado y elegido al azar,

para tratar de encontrar algún tipo de correlación que permitiera obtener un valor normal, lo cual no se consiguió.

Gráfico 4

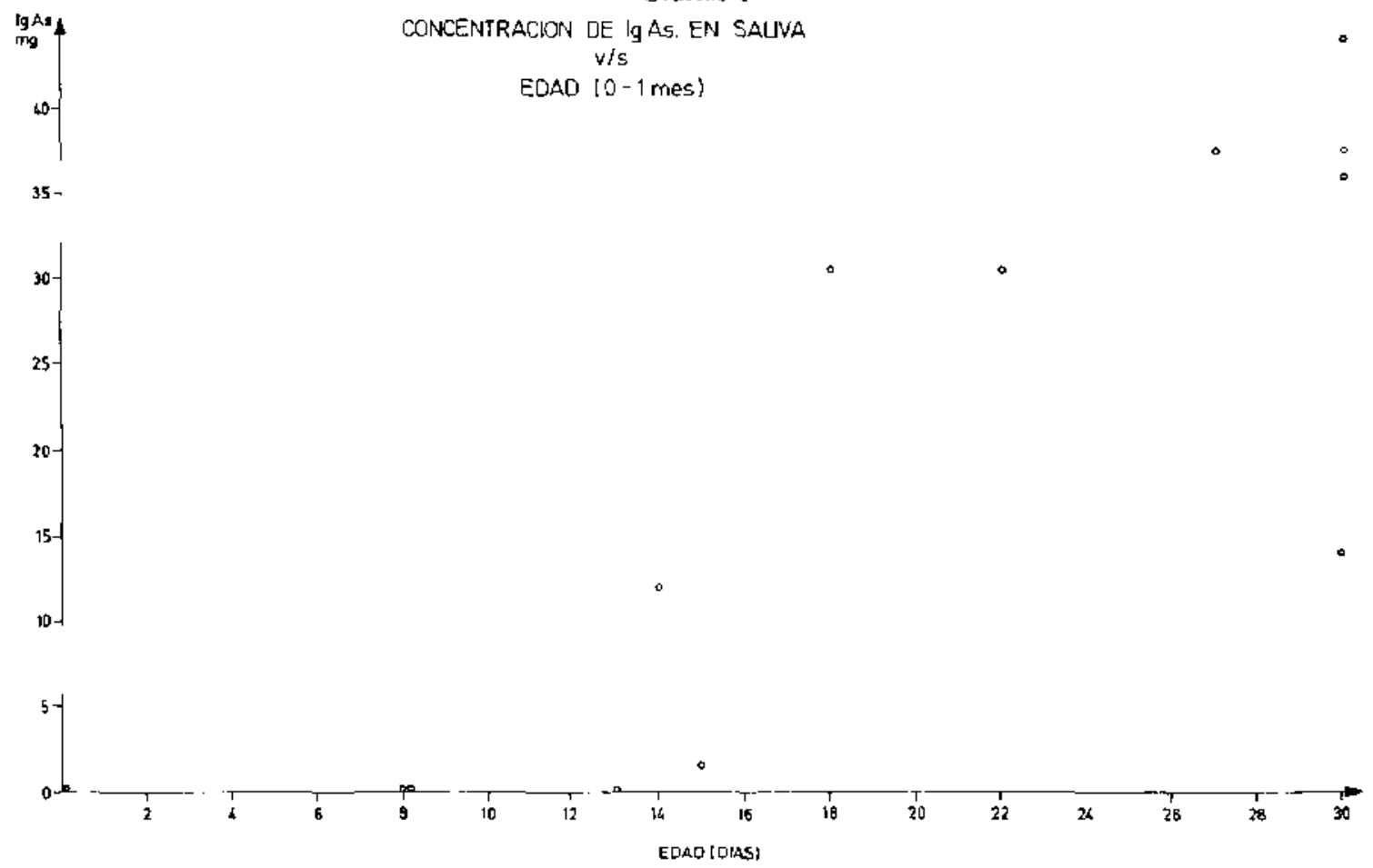

Grafico 5

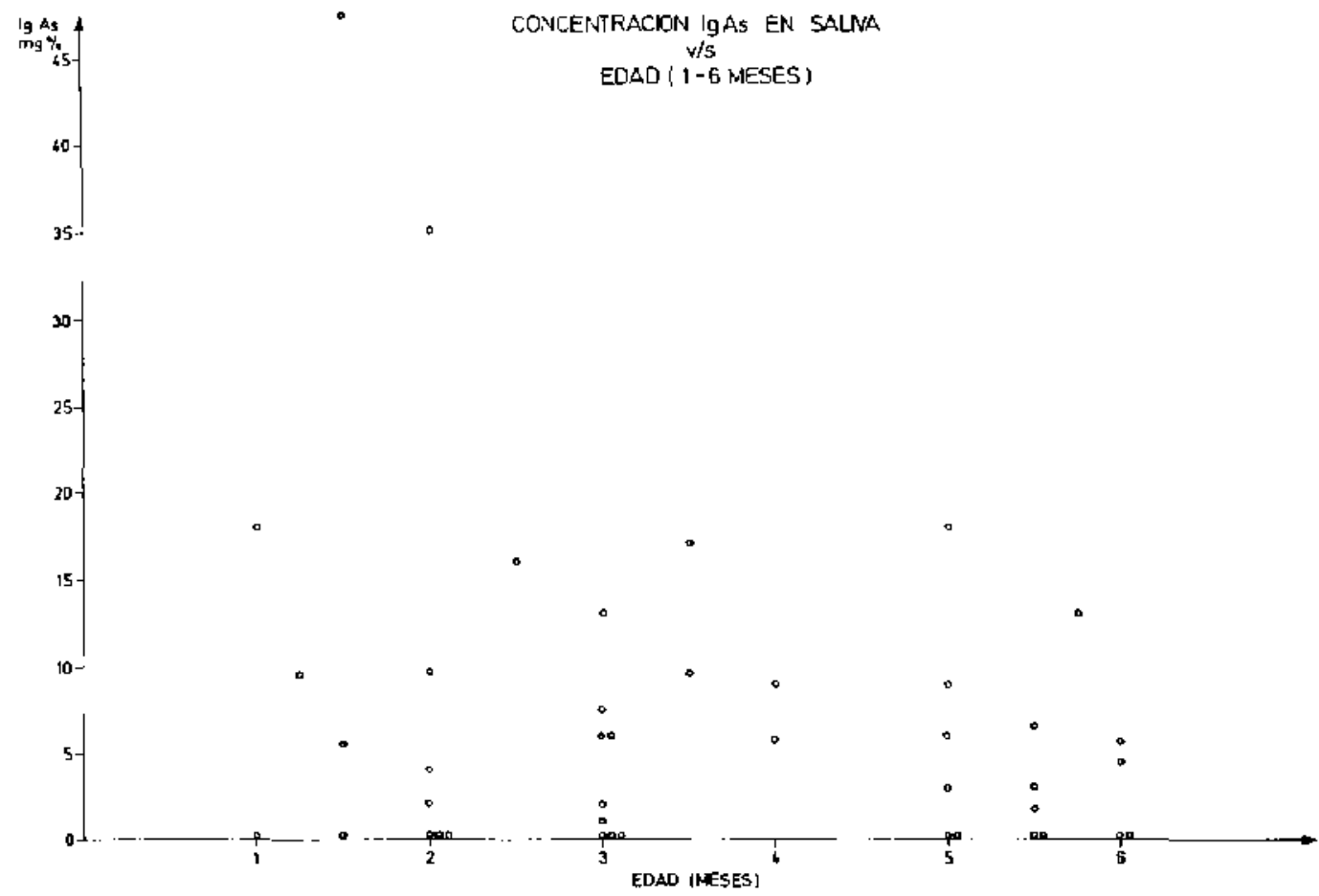


Gráfico 6

lg 45

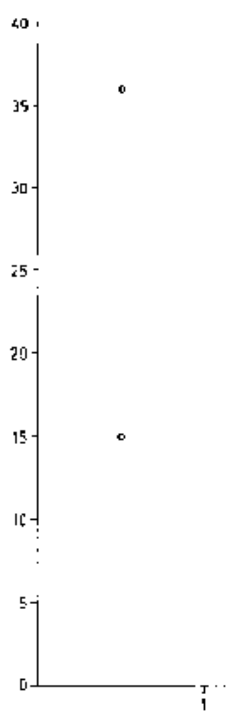

CONCERTRACION IQ AS EN SA LVA

vis

TIEMPC CE AY.JNO $\quad(2 \cdot 4$ ANNOS:

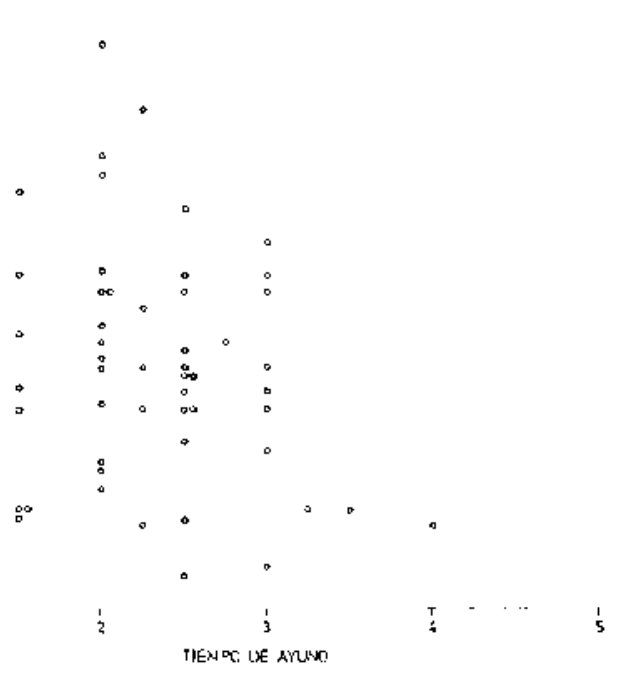

(iráfies :

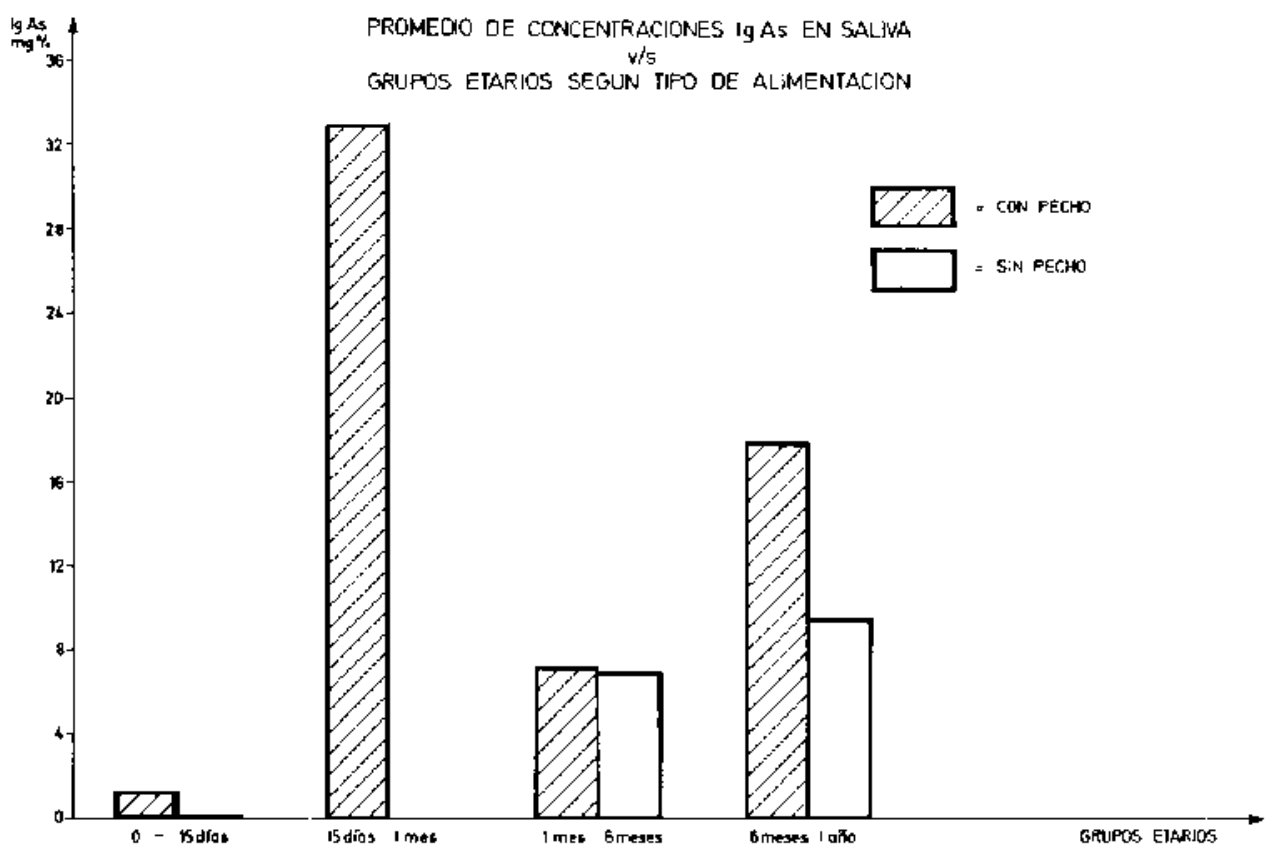

\section{Gráfico N. ${ }^{\circ} 6$}

Se observa que no existe una correlación definida entre el tiempo de ayuno a la toma de muestra y la concentración de Igas salival.

\section{Gráfico N. ${ }^{\circ} 7$}

De este gráfico se deduce que no hay una corre- lación clara entre los niveles de Igas salival y alimentación natural.

Debemos destacar que en el grupo etario de 15 días a 1 mes, la totalidad de los niños con que se trabajó estabau siendo alimentadus al pecho materno. 


\section{COMENTARIO}

Los niveles de Igas salival en nuestro medio no han sido determinados, sólo existen cifras sobre $\operatorname{los} 6$ años aportadas por el Departamento de Salud Pública de Chile.

Fundamentalmente hemos encontrado que en el recién nacido no hay niveles detectables por el método usado de Igas salival durante los primeros diez dias; entre los 10 y 15 dias aproximadamente y producida probablemente por la estimulación antigénica externa, los niveles de Igas comienzan a aumentar en forma considerable. Posteriormente, después del mes de edad los valores caen a 6,89 $\mathrm{mg} \%$ como promedio, posiblemente por el cese de esta estimulación antigénica masiva a que se ve expuesto el recién nacido. Desde esta edad en adelante el incremento de los valores promedio es progresivo $(12,13,12,95,15,40$, $16,44 \mathrm{mg} \%$ ) hasta alcanzar las cifras normales, estandarizadas para el adulto a que hemos hecho referencia,

No pudimos demostrar una relación de estos valores con respecto al tiempo de ayuno como tampoco con la alimentación natural, como esperábamos encontrar, pues es un hecho confirmado que los niños alimentados con pecho matemo tie- nen menor frecuencia de infecciones que los alimentados en forma artificial, por lo que estimamos que el mecanismo de protección podría estar en otros factores inmunológicos o en el conjunto de ellos que aporta la alimentación natural.

\section{REFERENCLAS}

* Bellariti.J.A. and Artenstein, M.S. "Mechanism of inmunity to virus infection". Pediatr. Clin. North Am. 1l: 558, 1964.

* Tomasi, I.B. Jri and Bienenstock, J. "Secretary Immunoglo. bulins". Adv. Inmunol. 9: 2, I968.

"Fudenberk, H.; Good, R.A.; Goodman H.C. et al. "Primary Immunndeficiences". Report of a World Health Organization Commuttee. Pediatrics 47: 427, 1971.

* Cooper, M.D. and all. "Classification of Primary Immunodeficiencies". New England J. Med. 288: 966-967, 1973.

* Thompson, RA.; Asquith, P. and Cooke, W.T. "Secretory Iga in the serum". Lancet II: 517, 1969.

- Waldman, R.M.: Mach, J.P.; Stella, M.M. and Rowe, D.S. "Secretory Iga in human senum". J. Immunol. 105: 43, 1970.

* Blork, KI. "The special relationship of lga and IgE antibodies to mucosal surfaces". In Bouheys, A. (ed.): Lung Cells in disease. Amsterdam, North Holland, 1976, pp. 183-196.

* Taylor, B.; Noman, A.P.; Orgel, H.A.; Stokes, C.R.; Turnes, M.W. and Soothill. J.F. "Transient Iga deficiency and pathogenesis of intantil atopy". Lancet 2: 111, 1973.

* Stercl. J. and Silverstein. A.M. "Developmental aspects of immunity". Adv. Immunol. 6: 337, 1967.

* Dancis, J, Oshom, JJ. and Kunz, H.W. "Studies of immuno$\log y$ of the newtom infant". IV Antibody formation in the premature infant. Pedintrics 12: 151, 1953. 